\title{
Asymmetric Reserve Power Delivered by Large Wind Power Plants
}

\author{
Kristof De Vos, Simon De Rijcke and Johan Driesen
}

\begin{abstract}
A stable and secure operation of the electricity grid is mainly achieved by contracting power generators to ancillary services in addition to their main commercial product, active power. Electricity from Renewable Energy Sources (RES-e) is today generally exempted from the participation in ancillary services. However, the increasing share integration of variable RES-e with a limited predictability has an impact on the demand and supply structure of these services. In this paper, the possibility of wind power participating in frequency control or delivering active power reserves as an ancillary service is investigated. Within this framework, technical, regulatory and economic aspects are examined and evaluated. As the specific details about the way ancillary services are contracted differ over Europe, a casestudy is done for the Belgian control zone. The consequence of offering an asymmetric reserve power, with only downward regulation, is economically assessed.
\end{abstract}

Index Terms - ancillary services, balancing, frequency control, reserve power, wind energy, wind power plants, wind power

\section{INTRODUCTION}

Tn 2008, 8.484 MW of wind power capacity was installed in the EU-27 (36\% of all new installed capacity) leading to a total wind power capacity of $65 \mathrm{GW}$ (Fig. 1). This accounted for $8 \%$ of total cumulative installed generation capacity (791 GW) at the end of 2008 (Fig. 2.), producing $142 \mathrm{TWh}$ of electricity, being 4,2\% of EU-27 demand [2]. In order to fulfil the ambitious 20/20/20 targets, the share of wind energy may increase further to $230 \mathrm{GW}$ of installed capacity by 2020 , with $40 \mathrm{GW}$ of offshore capacity. Concerning Belgium, in 2008, $104 \mathrm{MW}$ was installed leading to a total capacity of $384 \mathrm{MW}$ on-shore at the end of 2008. The first offshore projects are being constructed in the North Sea, with the aim to construct more than $600 \mathrm{MW}$ in the near future.

With the ever rising share of such renewable electricity, wind power will have to contribute to ancillary services, supporting the grid stability as well. This paper deals only with frequency control and active power reserves. In a first section, ancillary services are defined focusing on the different kinds of active power reserves in the framework of Belgian regulation and market structure. The second section describes the technical and economic feasibility of participation by wind power plants in these services. The paper ends with a case-study for a virtual wind power plant and the impact of different parameters as localization and

Manuscript received 30 October, 2009

J. Driesen, K.De Vos and S.Derijcke are with the research group ELECTA of the department electrical engineering of the K.U.Leuven (ESAT). Kasteelpark 10, 3001 Leuven, Belgium (e-mail: Kristof.DeVos@esat.kuleuven.be,_Simon.Derijcke@esat.kuleuven.be, Johan.Driesen@esat.kuleuven.be). type of wind generator on the technical availability and the economic cost of keeping a certain bandwidth as reserve. Asymmetric reserves, with only downward regulation are discussed.

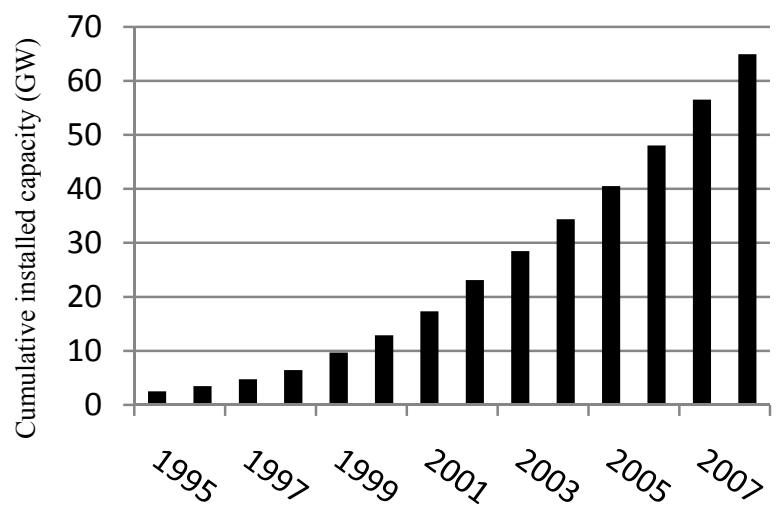

Fig. 1. Cumulative installed wind energy capacity in GW from 1995 until 2008 (source: EWEA)

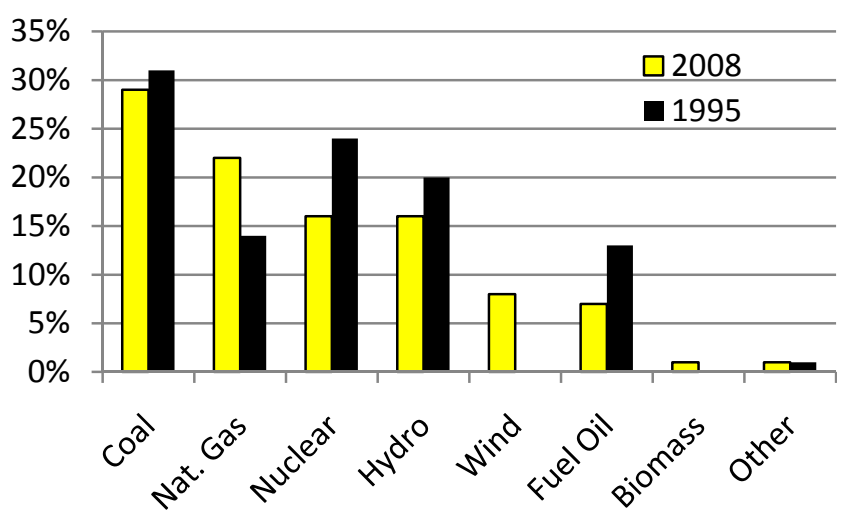

Fig. 2. Energy Mix EU for 2008 compared to 1995 (source: EWEA)

\section{ANCILLARY SeRVices}

To assure a reliable and secure electricity provision, system services such as stable voltage levels and a constant frequency have to be guaranteed. In unbundled electricity systems the Transmission System Operator (TSO), and partly the Distribution System Operators (DSOs), are responsible (and accountable) for a safe and reliable operation of the grid, so the provision of these services belongs to their basic obligations. These are typically contracted from (classical) generator companies, delivering them in addition or ancillary to active power.

With the unbundling of generation, transmission, distribution and retail, this became more complex. All grid users benefit together from a reliable grid whether an 
individual grid user participate in grid support or not. This leads to the specific issues of public goods and free rider problems.

As the contribution of RES-e increases, the share of conventional power plants delivering ancillary services decreases, so RES-e plants will have to (partially) compensate for this, and second, as renewable sources are often variable, not controllable and not entirely predictable [3] they are likely to have an impact on the need of ancillary services of a power system.

State-of-the-art wind power plants are technically capable of delivering some ancillary services such as voltage and frequency control (e.g. Horns Rev, the first off-shore wind plant in Denmark) [4], [5]. The main question is tough if availability and economic value of this participation by wind power is interesting enough under current market regulations.

\section{Frequency Control And Active Power Reserves}

Ancillary services are defined as "all services required by the transmission or distribution system operator to enable them to maintain the integrity and stability of the transmission or distribution system as well as the power quality [6]." System operators procure them mainly from generators, who deliver these services in addition or ancillary to their main product, namely active power. Consumers can also deliver such services, e.g. in the form of load shedding capability, which is in fact a form of asymmetric reserve power. In this paper, the focus is on frequency control and the delivery of reserve power, being two services that can be offered by wind power systems.

\section{A. Frequency control}

The frequency must be stabilized at 50 or $60 \mathrm{~Hz}$. This is achieved by maintaining an instantaneous balance of electricity generation and consumption. Each deviation from this balance leads to an increase or decrease in frequency which has to be counteracted by activating reserve power. Such reserve capacity can come from changing the operation point of a power plant, storage unit (e.g. pumped hydro) or consumers (load shedding). Before the reform of the electricity markets, with large national vertically integrated electric utility companies made frequency control relatively simple. The required reserve capacity was determined in order to operate within a certain safety margin and delivered by available generators within the same company.

To ensure the presence of enough reserve capacity, the TSO, responsible for the operation of the transmission grid, manages the provision of the necessary capacity. Generally, the system operator provides them by its own means or contracts them from other system users. In most cases they are contracted as most services are delivered by generators and system operators are in general, not allowed to own production capacity in liberalized markets.

An important issue is how these ancillary services should be procured and remunerated. Different procurement methods are described in literature as for instance compulsory provision, bilateral contracts, tendering or the spot market [7]. This can happen without remuneration or with a regulated, a bid or a common clearing price [7]. To summarize the two extreme cases, power producers could be obliged to be able to deliver certain ancillary services, with or without remuneration. The other option is to establish an open market where remuneration prices should be high enough to stimulate investments and delivery of the demanded services.

The rest of this section deals with the different kinds of reserve power which are discussed in the framework of the market, applicable for Belgium (Table 1). The classification corresponds generally to the ones in other countries of the ENTSO-E-zone ${ }^{1}$, though the specific requirements can be different per country [7], [8], [9].

\section{B. Primary Reserves}

Primary reserves are addressed automatically and the response time is in a time frame of a few seconds. After 15 seconds reserves have to be at $50 \%$ of contracted capacity and at full capacity after 30 seconds. These reserves are to be delivered for maximal 15 minutes [10]. Since liberalization in Belgium, primary reserves are contracted in an annual tendering system. Participants can submit bids to the Belgian TSO, Elia, for reserve blocks of $10 \mathrm{MW}$ which contains $5 \mathrm{MW}$ up and $5 \mathrm{MW}$ downward regulation. On day-ahead basis, participants have to submit to the TSO which production units will provide the reserves.

This sort of fast acting primary reserve is regulated on European level by the ENTSO-E. It defines that a certain amount of reserve capacity should be available for each country and this capacity has to be available $100 \%$ of the time [10]. Remuneration schemes for primary reserve may be different across Europe, but in Belgium these reserves are remunerated with a contracted fixed reservation price.

\section{Secondary Reserves}

Activation of secondary reserves is automatic upon instruction of the TSO, being Elia for Belgium, and have to be at full contracted capacity after 30 seconds and this for at least 15 minutes. Secondary reserves have two components:

\section{- $\quad$ Contracted secondary reserve}

This component is assigned via an annual tendering procedure. If a bid is selected by the TSO, the producer has to provide continuously the reserve power specified in the contract. This is remunerated by a reservation price. Each day (at $15 \mathrm{~h} 00 \mathrm{D}-1$ ), this capacity is offered on the reserve market in blocks of $10 \mathrm{MW}$ (similar to primary reserve). They are to be accepted by Elia in merit order [10]. The activation price of these bids are however capped in function of the market reference price and the fuel costs.

\section{- $\quad$ Free bids of secondary control power}

Additionally, bids can be freely submitted outside the annual tendering procedure if producers fulfill all technical requirements. These bids receive only the bid activation price.

\section{Tertiary Reserves}

Tertiary reserves serve to relief secondary and primary reserves and is thus in fact an economic (re)dispatch. It is activated manually and the response time has to be minimally 15 minutes and can be used until imbalance problems are disappeared limited to 8 hours. This kind of

\footnotetext{
${ }^{1}$ European Network of Transmission System Operators for Electricity, which took over the tasks of the Union for the Co-ordination of Transmission of Electricity (UCTE), the former association of transmission system operators in continental Europe.
} 
reserve can be contracted as well via production units as well as load shedding via consumers. We will focus on the tertiary reserve via production units having two components:

\section{- $\quad$ Contracted tertiary reserve}

Similar to primary and secondary reserves, tertiary reserves can be assigned via an annual call for tender. Remuneration exists consequently also in a reservation and activation price. This reservation price is determined by Elia and should compensate costs made for keeping capacity available. Activation price is contractually determined with a formula accounting for fuel costs and starting costs [10] This kind of reserve can only be activated upwards.

\section{- $\quad$ Forced bids of tertiary control power}

The Belgian grid code obliges each power plant with a nominal capacity larger than $75 \mathrm{MW}$ to bid non-nominated power capacity on the reserve market [3]. This applies in theory also on wind power plants but the grid code allows exceptions for RES-e. The participant in the tertiary reserve market has to submit these bids before gate closure $(14 \mathrm{~h} 00$, D-1). It contains a list with production units participating, reserve power available for each unit per 15 minutes and the bidding price.

\begin{tabular}{|c|c|c|c|}
\hline \multirow{2}{*}{ Reserve } & \multicolumn{3}{|c|}{ Remuneration fee } \\
\cline { 2 - 4 } & Tender & Free Bid & Forced Bid \\
\hline Primary & reservation & - & - \\
\hline Secondary & $\begin{array}{c}\text { reservation } \\
\text { activation }\end{array}$ & activation & - \\
\hline Tertiary & $\begin{array}{c}\text { reservation }+ \\
\text { activation }\end{array}$ & activation & activation \\
\hline
\end{tabular}

Table 1. The different contracting and remuneration schemes of reserve power in the Belgian market.

\section{Frequency CONTROL From Wind POWER Plants}

As shown in Fig. 3, different control techniques make wind power plants able to participate in frequency control [11]. Even the fast ramp-up rates needed for primary reserves are not a technical threshold for wind power participating in frequency control. However, as the wind power output depends on a variable power source with a limited predictability, this means that injection or absorption of active power cannot be guaranteed at all times. In practice, contracted reserves are never for $100 \%$ of the time available at $100 \%$ capacity. Introducing availability coefficients would make it possible to wind power plants to participate. As saying that $\mathrm{x}$ MW can be available at $\mathrm{x} \%$ of the time.

\section{Absolute power limitation Balance control Ramp rate limitation Delta control}

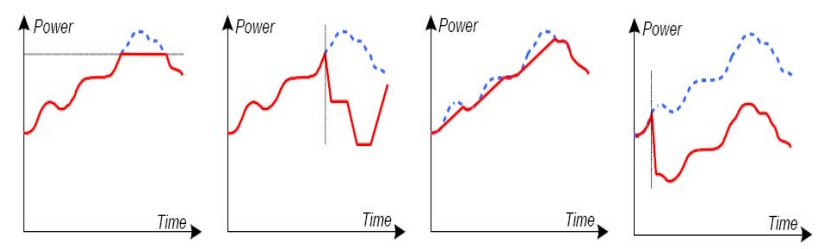

Fig. 3. Wind Power Plant Control in Horns Rev (Source: P. Sørensen) .
At this point, it can be questioned which is in fact the most economic alternative. Intuitively, the costs for wind power producers would be rather high in comparison with other technologies. A wind turbine, maintaining reserves has no variable costs (in contrast with thermal power plants saving fuel costs) but a high opportunity cost due to the lost green certificates (or other forms of support) next to the electricity value. Especially the participation in upward reserves is expensive as the wind power plant has to produce continuously under maximal capacity.

\section{A. Availability}

For primary reserves, as mentioned in section two, there is the requirement of the ENTSO-E to deliver this service at fulltime availability. This makes it however impossible for wind farms to participate as availability depend on a variable and not entirely predictable input. However, less tight standards may be defined in the future to have a certain capacity at a certain availability rate.

For secondary and tertiary reserves, $100 \%$ availability is not required in Belgium as long as a certain bandwidth is available on average basis. It should thus be technically possible for wind power plants to participate when sufficiently high availability rates could be reached. An important issue herein is the impact of prediction errors and nomination deadline (gate closure). In reality, reservation bids have to be nominated before real time (generally one day ahead) meaning that there has to be relied on forecasts with a limited reliability. This has a negative impact on the availability.

\section{B. Asymmetric Reserves}

Reserving and activating a reserve bandwidth imposes a cost for the participant (Fig. 4). This cost can be referred to as the opportunity cost where the better alternative is not to contract the active power reserves. In case of a wind power plant, this cost depends on the lost revenues of electricity and, if applicable, green certificates (proportional to the produced energy) that could have been cashed. When analyzing the total cost of delivering upward and downward reserves with wind power, four components can be defined (Fig. 4):

- upward reservation;

- upward activation;

- downward reservation;

- downward activation.

Concerning the reservation costs, wind power may have a priority dispatch, zero marginal cost and receives production support. This means that the most profitable strategy of a wind power plant is to produce all the time at maximal capacity. Consequently, keeping an upward bandwidth (bandUP) reserved imposes a lost revenue determined by the price of electricity (E) and certificates (GC). On the other hand, keeping the downward bandwidth (bandDOWN) reserved has no opportunity cost at all as the wind power plant has as such an incentive to produce at maximal capacity. Hence, asymmetrical results are obtained. 


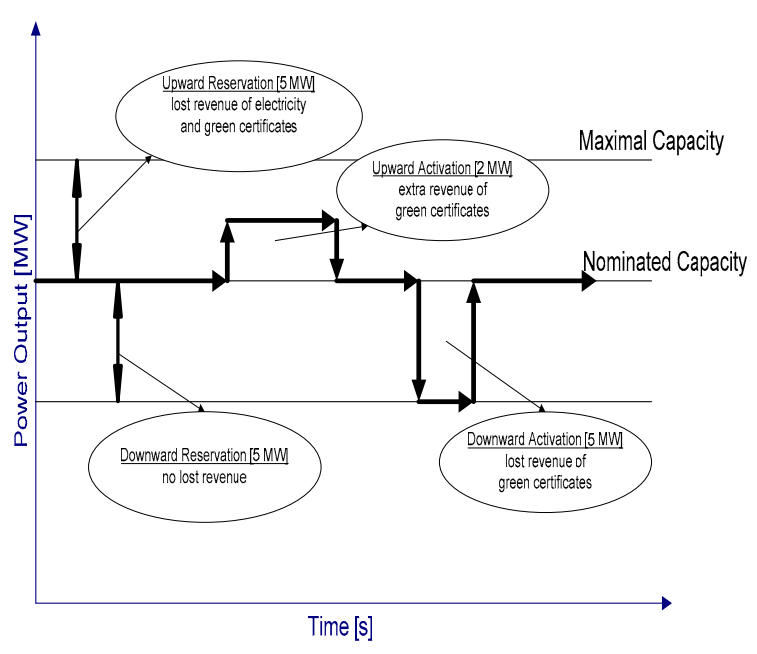

Fig. 4. Costs and revenues linked to reservation and activation of reserves by wind power plants

The hourly reservation costs of contracting a certain bandwidth of reserve power can be calculated as: reservation upward: $(\mathrm{E}+\mathrm{GC}) \mathrm{x}$ bandUP reservation downward: 0

When these hourly costs are aggregated over a whole year, the yearly reservation cost is found for a wind power plant holding reserves. This cost is only determined by the lost revenues of keeping the upward reserves. If this reserve bandwidth was available for $100 \%$ of the time, this cost becomes:

$$
(E+G) \times \text { bandUP } \times 8760 \text { hours }
$$

If less than $100 \%$ availability of the contracted bandwidth is allowed, this influences the opportunity cost (if the reserve bandwidth cannot be activated as there is no wind available, there are also no lost revenues to be assigned). If for instance the contracted bandwidth can only be available for $70 \%$ of the time and in the other $30 \%$ of the time there is no wind the formula becomes:

$$
(\mathrm{E}+\mathrm{GC}) \times \text { bandUP } \times 8760 \times 0.70
$$

However, if in this remaining $30 \%$ the maximal wind power capacity (Pcap) was smaller than the contracted bandwidth but larger than zero, the opportunity cost becomes (Fig. 5):

$$
(\mathrm{E}+\mathrm{GC}) \times \text { Pcap }
$$

The hourly opportunity costs are thus also dependent of the wind power output $(\mathrm{P})$ and the hourly cost can be modeled as:

$$
\begin{aligned}
& (\mathrm{E}+\mathrm{GC}) \mathrm{x} \text { bandUP } \mathrm{x} \text { IF } 1+(\mathrm{E}+\mathrm{GC}) * \text { Pcap } * \mathrm{IF} 2 \\
& \mathrm{IF} 1=1 \text { if } \mathrm{P} \geq \text { Pcap, } 0 \text { if not } \\
& \mathrm{IF} 2=1 \text { if } \mathrm{P}<\text { Pcap, } 0 \text { if not }
\end{aligned}
$$

Concerning the activation costs, they only depend on the green certificates. When reserves are activated, this is not submitted to the imbalance mechanism. The participant activating its reserves counteracts on an imbalance created in the system, and the TSO considers it as its normal nominated power was delivered. Result is that there is no impact on the revenues of electricity when activating upward or downward reserves. On the other hand, activation has an impact on the registered power production which determines the amount of green certificates to be received. The activation cost thus only depends on the certificates and the activation volume (Vol.Act) which can be expressed in MWh.

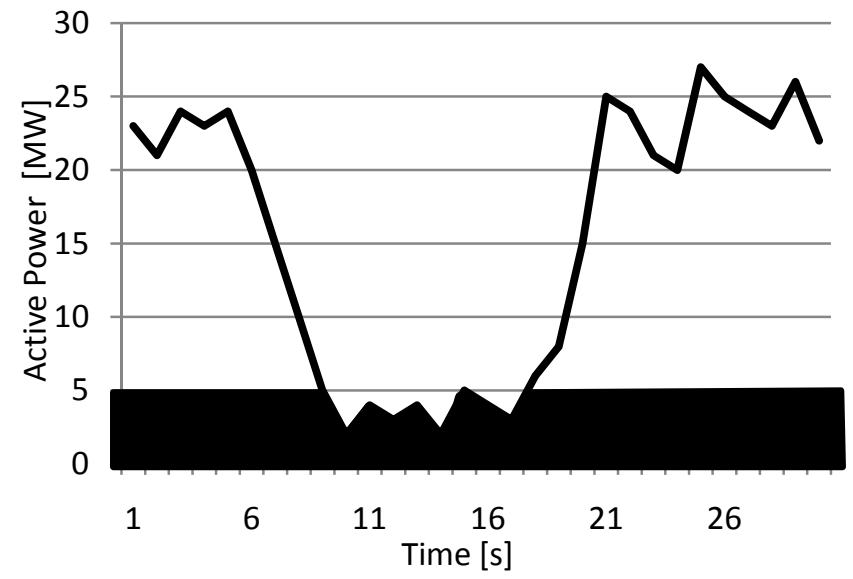

Fig. 5. Reservation cost of a $5 \mathrm{MW}$ bandwidth

The activation costs over a certain period are calculated as:

activation upward: - GC x Vol.Act.UP activation downward: GC x Vol.Act.DOWN (7)

Note that if upward and downward activation volumes are equal, these terms cancel each other out and the total activation cost becomes zero. This assumption is in reality only correct for primary reserves.

If the total cost of keeping reserves by wind power is modeled for a certain period, reservation costs have to be aggregated over this period and added to the total activation cost in this period:

$$
\begin{aligned}
& \text { upward: } \sum[(\mathrm{E}+\mathrm{GC}) * \text { bandUP }]- \\
& \text { GC Vol.Act.UP } \\
& \text { downward: GC Vol. Act. UP }
\end{aligned}
$$

When upward and downward reserves are activated in equal volumes, this becomes:

$$
\sum[(\mathrm{E}+\mathrm{GC}) * \text { bandUP }]
$$

This corresponds to the opportunity costs where the better alternative was to produce at maximal power. This opportunity cost is what is to be paid to the supplier of reserve power to make him to participate voluntary in this market.

\section{Economic Feasibility}

As total costs from keeping reserves by wind power come from the upward bandwidth, it might be interesting to contract this power source only for downward regulation. In this case the opportunity costs are limited to the lost green certificates during activation periods. A possible portfolio is for instance wind power for the downward and classic fuel driven thermal plants or load control for the upward part. 
This is theoretically already possible in Belgium intra-BRP (balancing responsible party): a BRP contracts the reserves and it is allowed to use different units for the downward and upward regulation.

It has to be noted that although using wind power only for the downward regulation is economically more interesting, the cost when activating these reserves may still be higher than alternatives due to lost green certificates and saved fuel costs in case of thermal plants.

When constructing the model to calculate the opportunity costs of the supply of reserve power by wind power plants, no distinction has been made between the three different types of reserves. However, secondary and tertiary reserves are different from primary reserves. As it was fair to assume an equal activation volume of upward and downward reserves in the case of primary reserves, secondary and tertiary reserves are activated more in the downward direction. This is explained by the fact that more electricity is often nominated than consumed. A second difference is that creating asymmetric products becomes difficult as most participants prefer to deliver downward reserves.

Participating in secondary and tertiary control is normally not interesting for wind power due to the same reasons as primary control. Activation and reservation prices have to compensate opportunity costs of electricity and green certificates and as reserves are contracted and activated according to merit order, wind power is not able to compete with other capacity. In Belgium, wind parks larger than 75 MW should in theory participate in the bidding process, but can be exempted by the TSO as RES-e. It is not interesting for a wind producer to submit incremental bids as they are too expensive. Decremental bids however can be more attractive as only the activation cost has to be remunerated. These costs are determined by the lost green certificates.

\section{CASE-STUdy: Asymmetric Reserve POWER From A HIGH-CAPACITY WIND PLANT}

To evaluate technical availability and economic value of the provision of (asymmetric) active power reserves for frequency control by high capacity wind parks, a model is built converting real-time wind data into active power output for a virtual wind park. This enables us to evaluate the availability of a certain bandwidth for reserves together with the opportunity costs (lost revenues) compared to the alternative where the wind park does not participate in the delivery of this ancillary service.

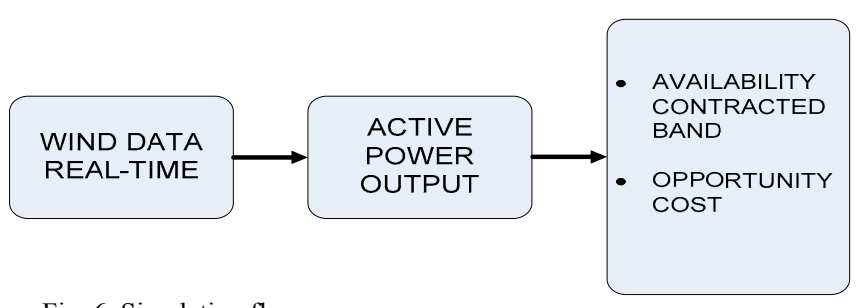

Fig. 6. Simulation flow.

For this case study, real-time wind data are taken from the Royal Netherlands Meteorological Institute for three different locations (Fig. 6): Eindhoven (inland), Vlissingen (coastal) and the plain of De Raan (offshore) for 2008 [12], all situated near the Belgian-Dutch border, on an West-East axis. The data acquired are potential wind speeds meaning that they are wind speeds measured on location and recalculated as it was measured in open terrain at 10 meters height (roughness 0,03 on-shore and 0,002 offshore). With these roughness coefficients, wind speeds are recalculated for hub height of the turbines according to the power law wind profile.

The model is built for two different kinds of wind turbines. In a first part, calculations are done for the Vestas V90 3 MW turbines with a hub height of 80 meters and a power curve described in Fig. 7 [13]. This wind turbine was introduced in 2002 and has a relatively high rated wind speed $(15 \mathrm{~m} / \mathrm{s})$ and cut-in speed $(4 \mathrm{~m} / \mathrm{s})$ [14]. This turbine can still be found in the product line of Vestas but newer and better turbines are available today. They attain lower rated wind speed $(12 \mathrm{~m} / \mathrm{s})$ and cut-in speed $(3 \mathrm{~m} / \mathrm{s})$ which has a positive impact on the power output. Therefore, calculations are repeated in a second phase for a Vestas 112 3 MW turbine with a power curve as shown in Fig. 7. The latter turbine has a slightly higher hub height but due to the low roughness coefficients, this difference is neglected. Capacity factor and time at rated wind speed are calculated for the available wind data and is shown in Table 2 .

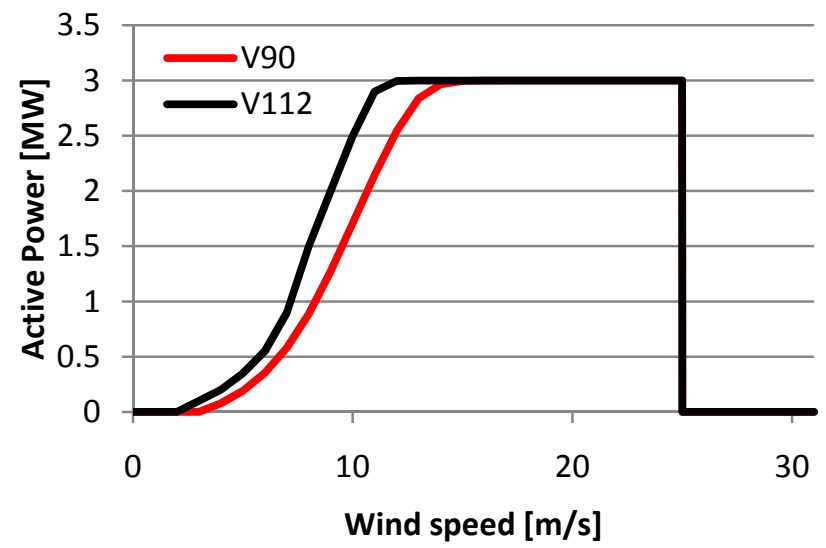

Fig. 7. Power curve of the V90 3 MW and V112 3 MW turbines (source: Vestas)

\begin{tabular}{l|cc|cc}
\hline & \multicolumn{2}{|c|}{ Capacity } & Factor [\%] & \multicolumn{2}{c}{$\%$ at Nominal Power } \\
\hline & V90 & V112 & V90 & V112 \\
Inland & 10,03 & 16,52 & 0,02 & 0,75 \\
Coastal & 22,98 & 32,79 & 1,25 & 6,57 \\
Off-shore & 34,08 & 45,99 & 1,47 & 10,88 \\
\hline
\end{tabular}

Table. 2. Characteristics of the Vestas V90 and V112 Turbine.

As specific data about entire wind farm power curves is not available, the next step should be to construct these. This is complicated as multi-turbine power curve are not just the sum of the single turbines in the park due to wake effects amongst others. These effects will smooth the aggregated power curve: cut-in becomes lower, cut-out higher and a more curved path at rated wind speeds. In this case-study the power curve without smoothing effects had to used as no specific data was available. This is justified as for a wind power plant which is not too large in surface, smoothing effects remain minimal.

\section{A. Availability}

Based on a power curve, hourly wind speeds are converted into active power capacities for a wind power plant. This means a theoretical availability can be calculated for a certain reserve bandwidth. In Fig. 8 (V90-turbine) and Fig. 9 (V112-turbine), the availability is evaluated for different bandwidth sizes (expressed in percentage of the rated power of the wind farm). First of all, a large difference can be seen between the three locations. This difference can 
intuitively be understood as average wind speeds are higher off-shore than on-shore as can be seen in Table 3. Second, there is a large difference between the V90-turbine and the V112-turbine. Much higher availability rates can be attained with the more modern turbines due to the lower cut-in speed. A third observation is that the availability rates tend to converge as park size increases. This can be explained by the time frames where wind speeds are zero and no output can be delivered regardless of wind park size. The most important conclusion however is that a bandwidth of $10 \mathrm{MW}$ (which is the minimal bandwidth that can be contracted in Belgium) can be delivered by reasonable park sizes with sufficient availability rates (Table 3 ). This is certainly the case for off-shore locations, but even for coastal areas with state-of-the-art turbines.

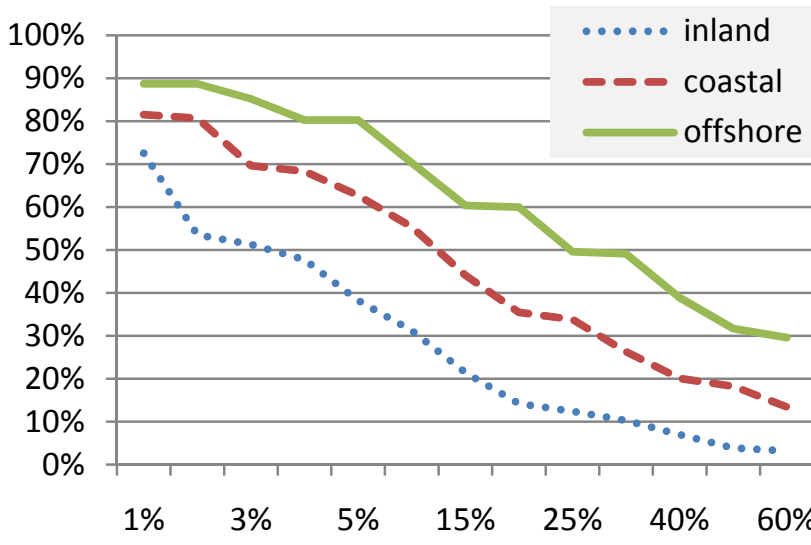

Reserve Bandwitdh (\% of wind park capacity)

Fig. 8. Availability reserve bandwidth in function of size bandwidth expressed in percent of nominal power wind park with V90-turbines.

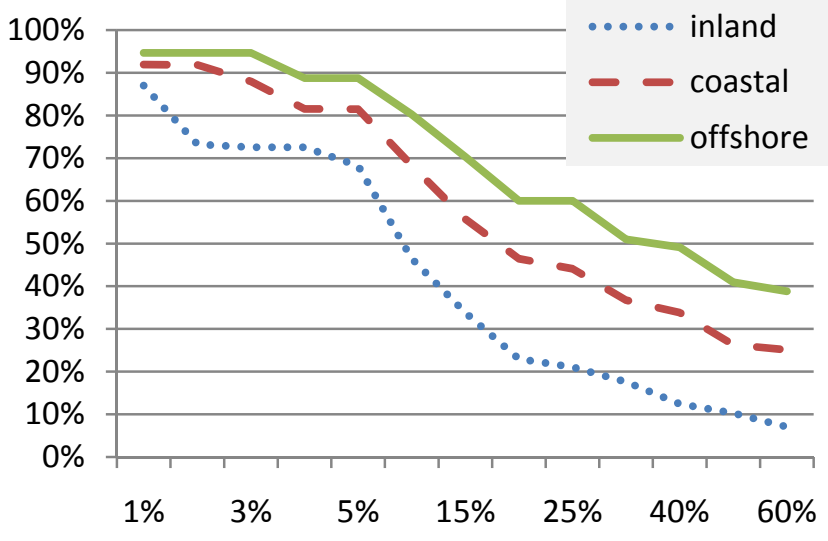

Reserve Bandwitdh (\% of wind park capacity)

Fig. 9 Availability reserve bandwidth in function of size bandwidth expressed in percent of nominal power wind park with V112-turbines.

In Fig. 8 and Fig. 9, decreasing paths of the availability can be observed if the reserved bandwidth becomes larger for a certain wind park. It can be concluded that a reserve bandwidth of $10 \%$ of the nominal power of the wind power plant can be attained with an availability of $31 \%, 55 \%$ and $70 \%$ for the older V90 turbine respectively for inland, coastal and off-shore. For the newer turbines, these numbers increase even to $47 \%, 68 \%$ and $80 \%$ (Table 4 ).

As can be seen in Table 3 and Table 4, availability improves significantly if the bandwidth is reduced. The results of a $5 \mathrm{MW}$ bandwidth can be interpreted as the availabilities when only the upward or the downward part is contracted by the wind park producer. As already explained, it may be interesting to contract only the downward part from wind generators.

\begin{tabular}{|c|c|c|c|c|c|c|}
\hline & \multicolumn{2}{|c|}{ On-shore } & \multicolumn{2}{c|}{ Coastal } & \multicolumn{2}{c|}{ Off-shore } \\
\hline Turbine & V90 & V112 & \multicolumn{2}{|c|}{ V90 } & V112 & \multicolumn{2}{c|}{ V90 } & V112 \\
\hline $\begin{array}{c}\text { Average } \\
\text { wind speed } \\
\text { [m/s] }\end{array}$ & \multicolumn{2}{|c|}{4,62} & \multicolumn{2}{|c|}{6,43} & \multicolumn{2}{c|}{7,68} \\
\hline $\begin{array}{c}\text { Maximal } \\
\text { availability } \\
{[\%]}\end{array}$ & 72,6 & 90,0 & 85,8 & 95,1 & 92,5 & 98,4 \\
\hline $\begin{array}{c}\text { Park size } \\
\text { for 70\% } \\
\text { availability } \\
{[5 \text { MW] }}\end{array}$ & 480 & 108 & 180 & 69 & 60 & 27 \\
\hline $\begin{array}{c}\text { Park size } \\
\text { for 70\% } \\
\text { availability } \\
{[10 \text { MW] }}\end{array}$ & 960 & 216 & 336 & 132 & 96 & 60 \\
\hline
\end{tabular}

Table 3 Availabilities of reserve bandwidths of $5 \mathrm{MW}$ and $10 \mathrm{MW}$.

\begin{tabular}{|c|c|c|c|c|}
\hline$\%$ & \multicolumn{2}{|c|}{$\mathbf{1 0}$ MW } & \multicolumn{2}{c|}{5 MW } \\
\hline Turbine & V90 & V112 & V90 & V112 \\
\hline On-shore & 31,12 & 46,51 & 38,23 & 68,21 \\
\hline Coastal & 55,38 & 68,34 & 62,69 & 81,50 \\
\hline Off-shore & 70,31 & 80,25 & 80,25 & 88,73 \\
\hline
\end{tabular}

Table 4 Availabilities of reserve bandwidths of $5 \mathrm{MW}$ and $10 \mathrm{MW}$.

An important simplification of the model is that in this case-study, nomination is assumed to happen in real-time. In reality, this nomination of reserve power happens dayahead, meaning a certain prediction error exists having a negative impact on the availability rates. On the other hand, with intra-day nominations possible, this negative impact will be damped.

\section{B. Economic evaluation}

In the previous section, the conclusion was that the availability of certain bandwidths may be high enough to be interesting for participation by wind power. For instance, as shown in Table 3, an availability of above $70 \%$ can be attained for reasonable park sizes. The main issue now is whether this is also interesting from the economic point of view. A wind power producer will only participate voluntary in the reserve market if the remuneration he may receive covers at least his extra costs. As already explained in section IV, these extra costs for wind power are the lost revenues of the active power he cannot sell. These costs depend on electricity price (plus support mechanism if present), availability and size of the bandwidth.

In this case-study, the Belgium market situation is used as reference. A Balancing Responsible Party (BRP) may contract reserve bandwidth with the system operator for blocks of 10MW, meaning $5 \mathrm{MW}$ up- and $5 \mathrm{MW}$ downward regulation. If this cost is to be modeled for wind power, the lost revenues are calculated per hour after which they are aggregated for a whole year. The lost revenues depend on electricity prices (data used form the BelPex Spot Market [15]), increased with the average price of green certificates for wind power in 2008, which was $€ 88,22$ for 2008 [16]. The hourly electricity price is taken into account as using the average electricity price would distort results due to higher prices in daytime than at night (when less wind is produced). The main problem with the BelPex data is however that in reality, electricity is sold with long-term 
over-the-counter contracts, being cheaper due to reduced risks. Average electricity price in 2008 was also rather high $(€ 70,62)$ which may overestimate revenues.

In Fig.10 and Fig. 11, the lost revenues of keeping reserves are visualized as a function of the size of the bandwidth. The results show that these opportunity costs rise with increasing size of the contracted bandwidth, newer turbines and localization closer to sea. This is explained by the fact that the lost revenues increase with higher availabilities.

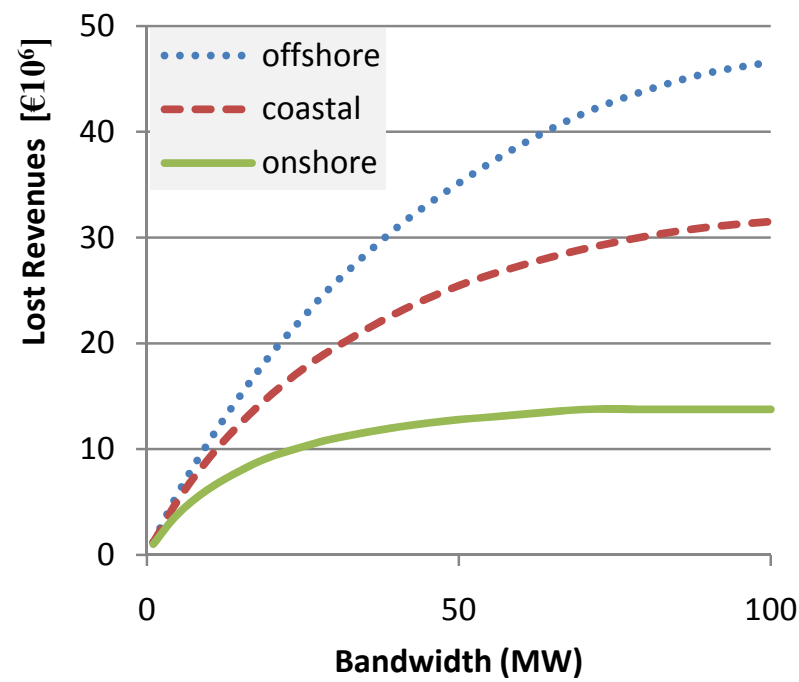

Fig. 10 Opportunity cost in function of bandwidth size for a wind power plant with a rated power of $100 \mathrm{MW}$ (V90).

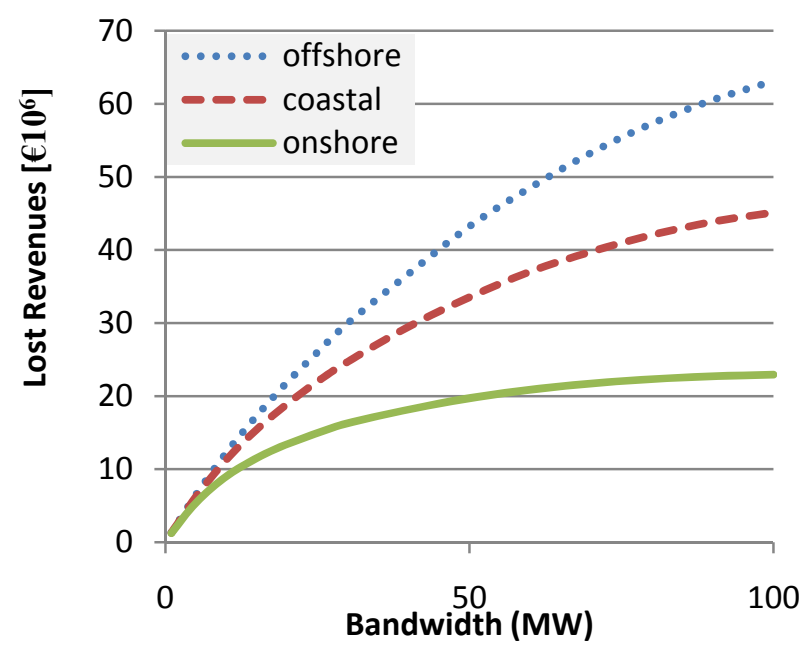

Fig. 11. Opportunity cost in function of bandwidth size for a wind power plant with a rated power of $100 \mathrm{MW}$ (V112).

Besides all technical requirements that can be fulfilled to facilitate the participation of wind parks in the delivery of reserve power (except demanding a 100\% availability), costs to do so are relatively high (Table 5). This is due to a zero marginal cost and green certificates. A wind power producer receives the price of electricity plus a green certificate per MWh in comparison to the price of electricity minus the marginal production cost (fuel) in case of a classic thermal generator. Prices paid by the TSO to acquire this service on voluntary basis must be compared with other technologies and are for sure too high to be competitive. In order to get wind power plants to participate, one option is to oblige them trough regulation to keep a certain percentage of their maximal output in reserve to assure grid stability.

\begin{tabular}{|l|c|c|c|c|}
\hline \multicolumn{1}{|c|}{$\begin{array}{c}\text { Lost Revenue } \\
{\left[€ 10^{6}\right]}\end{array}$} & \multicolumn{2}{c|}{$5 \mathrm{MW}$} & \multicolumn{2}{c|}{$10 \mathrm{MW}$} \\
\hline Turbine & V90 & V112 & V90 & V112 \\
\hline Inland & 3,90 & 5,37 & 6,3 & 9,0 \\
\hline Coastal & 5,23 & 6,17 & 9,2 & 11,3 \\
\hline Off-shore & 5,87 & 6,45 & 10,8 & 12,2 \\
\hline
\end{tabular}

Table 5. Economic cost of keeping a reserve bandwidth of $5 \mathrm{MW}$ from a wind park of $100 \mathrm{MW}$.

A second solution is to adapt market rules in a way that it becomes allowed for wind producers to submit asymmetric bids for only a certain amount of downward regulation. This means that the producer does not have to produce the whole year under maximal capacity. Reservation costs in this case become zero and the only cost is the activation cost depending on green certificates and activation volume. This is already possible in Belgium intra-BRP.

\section{CONCLUSIONS}

Wind power plants are today technically able to participate in frequency control and the provision of reserve power capacity. This as well for the primary, secondary and tertiary type. Different case-studies exist as such as Horns Rev and undiscriminating grid requirements for wind power in Ireland. More and more, having the ability to deliver reserve power or disposing of frequency control capabilities becomes compulsory for wind power plants that want to be connected to the grid.

Concerning the theoretically availability of reserve power delivered by a wind power plant, the conclusion is that reasonable values can be attained, certainly for coastal and off-shore locations. A bandwidth of $5 \%, 10 \%$ of the rated power of a wind farm can be kept reserve up to respectively $89 \%$ and $80 \%$ of the time for an off-shore farm with stateof-the-art turbines. These turbines (with a lower cut-in wind speed) improve availability rates significantly in comparison with older models. A second variable is the localization of the wind power plant: the availability of a bandwidth is higher off-shore than on-shore.

The economic costs of delivering a certain bandwidth as reserve capacity corresponds to the lost revenues of the electricity that could have been sold and the additionally production support (green certificates, feed-in tariffs, feed-in premiums). The main conclusion here is that keeping reserves by wind power plants is relatively expensive due to production support mechanisms and negligible marginal costs. A possible solution is to use wind power asymmetrically, being only for downward regulation and other production units (or load control) as upward regulation. This would eliminate the large opportunity costs for RES-e producing constantly under maximal power capacity. The only remaining cost is the activation cost of the downward reserves which is determined by the lost certificates and activation volume. Further research is therefore to be directed to the comparison of the costs of frequency control for different technologies and the optimal combinations for up- and downward regulation.

The assumption made in this study concerning the realtime nomination is also subject for further research. In reality, nominations have to be send to the TSO before a certain deadline which leads to prediction errors and has negative impact on the availability of the reserved bandwidth. 


\section{REFERENCES}

[1] European Commission (2008) "Memo on the Renewable Energy and Climate change Package", MEMO/08/33, Brussels, 23 January 2008

[2] European Wind Energy Association (2009) "Wind Energy Statistics", February 2009, www.ewea.org

[3] De Vos, K. and Driesen, J. (2009) "Balancing Management Mechanisms for Intermittent Power Sources - A Case-Study for Wind Power in Belgium)", accepted for presentation for the Conference on European Energy Markets 2009.

[4] Hansen, A., Sørensen, P., Iov., F., Blaabjerg, F. (2006) "Centralised Power Control of Wind Farm with Doubly Fed Induction Generators" Renewable energy vol. $31 \mathrm{nr} .7$ (2006) p.935

[5] Sørensen, P., Hansen, A., Thomsen, K., Buhl, T., Morthorst, T. et al. (2005) "Operation and Control of Large Wind Turbines and Wind Farms - Final Report” Risø Report, Risø-R-1532 (EN), Risø National Laboratories, September 2005

[6] EURELECTRIC (2003) "Ancillary Services: Unbundling Electricity Products - An Emerging Market”, February 2004, Ref:2003-1500007

[7] Rebours, Y., Kirschen, D., Trotignon, M., Rossignol S. (2006) “A Survey of Frequency and Voltage Control Ancillary Services - Part II: Economical Features" IEEE transactions on power systems, vol. 22, Nr.1(2007), p.358

[8] ETSO (2003) "Current State of Balance Management in Europe" December 2003, www.etso.be

[9] Rebours, Y., Kirschen, D., Trotignon, M., Rossignol S. (2006) “A Survey of Frequency and Voltage Control Ancillary Services - Part I: Technical Features" IEEE transactions on power systems, vol. 22, Nr.1(2007), p.350

[10] ELIA (2007) "Product Sheets" www.Elia.be

[11] Kristoffersen, J. "The Horns Rev Wind Farm and the Operational Experience with the Wind Farm Main Controller", Copenhagen Offshore Wind 2005, (26-28 October 2005)

[12] Koninklijk Nederlands Meteorologisch Instituut (2009) "Potential Wind Speeds of the Netherlands", www.knmi.nl, last consulted $15 / 5 / 2009$

[13] Vestas, "Product Sheets V90 and V112", www.vestas.com, last consulted 13/5/2009

[14] EWEA (2009) , "Wind Energy - The Facts", Earthscan, pp. 488

[15] Belpex, market data www;belpex.be, last consulted 13/5/2009

[16] CWAPE (2009), Prix de transaction des CV, www.cwape.be, last consulted 13/5/2009

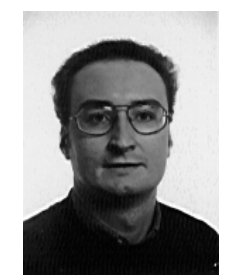

Johan Driesen (S'93-M'97) was born in 1973 in Belgium. He received the M.Sc. degree in 1996 as Electrotechnical Engineer from the K.U. Leuven, Belgium. He received the Ph.D. degree in Electrical Engineering at K.U.Leuven in 2000 on the finite element solution of coupled thermal-electromagnetic problems and related applications in electrical machines and drives, microsystems and power quality issues. Currently he is an associate professor at the K.U.Leuven and teaches power electronics and drives. In 2000-2001 he was a visiting researcher in the Imperial College of Science, Technology and Medicine, London, UK. In 2002 he was working at the University of California, Berkeley, USA. Currently he conducts research on distributed energy resources, including renewable energy systems, power electronics and its applications, for instance in renewable energy and electric vehicles.

\section{BIOGRAPHIES}

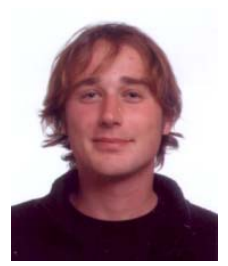

Kristof De Vos was born in Belgium in $1985 . \mathrm{He}$ received his master in commercial engineering in 2008 at the Faculty of Business and Economics of the K.U.Leuven/Belgium. Since 2008, he is working as a research assistant towards a $\mathrm{Ph} . \mathrm{D}$ in the research group ELECTA, department of Electrical Engineering of the K.U.Leuven/Belgium. His field of interest is the integration of renewable and distributed energy resources into the electricity system.

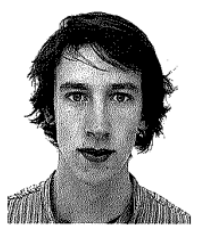

Simon De Rijcke (S'2008) was born in Belgium, on May 26, 1986. He graduated as an electrotechnical engineer from the Katholieke Universiteit Leuven (KULeuven) in 2009 and received a master in energy. Since 2009, he is working as a research assistant towards a Ph.D. in the research group ELECTA, department of Electrical Engineering of the KULeuven. His field of interest is the integration of renewable energy sources in the electricity system. 